\title{
Detection of four calla potyviruses by multiplex RT-PCR using nad5 mRNA as an internal control
}

\author{
Wen-Chi Hu • Chin-Hsing Huang • \\ Shu-Chuan Lee $\cdot$ Chun-I Wu $\cdot$ Ya-Chun Chang
}

Received: 14 February 2009 / Accepted: 2 July 2009 /Published online: 15 July 2009

(C) KNPV 2009

\begin{abstract}
Dasheen mosaic virus (DsMV), Turnip mosaic virus (TuMV), Konjac mosaic virus (KoMV) and Zantedeschia mild mosaic virus (ZaMMV) are important potyviruses previously identified in calla lily plants in Taiwan. In order to save time and cost of virus detection, a multiplex RT-PCR assay was developed for these calla potyviruses. Specific primers for each virus were designed based on the sequences of $3^{\prime}$ terminal region of respective viruses. To prevent false negative results, a primer pair specific to plant mitochondrial nad5 mRNA was used to produce a 185-bp fragment as an internal control of RT-PCR. The specificities of primers were confirmed by means of simplex and multiplex PCR assays. Optimal primer concentration ratio was identified by multiplex PCR assay. Total RNAs purified from virus-infected plants were used directly or mixed in different combinations, and then tested by multiplex RT-PCR. The result indicated that the expected RT-PCR products could be specifically amplified and identified on the basis of their molecular sizes. The detection sensitivity of multiplex RT-PCR was 25-625 times higher than that of indirect-ELISA (I-ELISA) depending on the virus. When applied to
\end{abstract}

W.-C. Hu • C.-H. Huang $\cdot$ S.-C. Lee $\cdot$ C.-I. Wu $\cdot$

Y.-C. Chang $(\bowtie)$

Department of Plant Pathology and Microbiology,

National Taiwan University,

No. 1, Sec 4, Roosevelt Road,

Taipei 10617, Taiwan

e-mail: ycchang@ntu.edu.tw field surveys, multiplex RT-PCR could detect more single as well as mixed infection samples than I-ELISA. Accordingly, our multiplex RT-PCR assay provides a simple, rapid and reliable method for multiple potyvirus detection in calla lily.

Keywords Calla lily · Detection · Multiplex RT-PCR . Potyvirus

\section{Introduction}

Calla lily is the common name of the members of Zantedeschia spp. which belong to the family Araceae and are classified into seven species and two subspecies (Kuehny 2000). As tropical plants native to Africa, calla lilies are now grown as outdoor garden plants, cut flowers and flowering potted plants. Many cultivars of calla lily have been introduced into Taiwan from New Zealand, the Netherlands and the USA for $>10$ years. However, virus diseases are one of the major factors limiting calla lily production (Chen et al. 2003; Huang et al. 2007). Calla lily has been reported as the natural host of various plant viruses, mainly potyviruses (Huang et al. 2007). There are six potyviruses identified in this plant and five of them have been found in Taiwan, including Calla lily latent virus (CLLV) (Chen et al. 2004), Dasheen mosaic virus (DsMV) (Chen et al. 1998), Turnip mosaic virus (TuMV) (Chen et al. 2003), Zantedeschia mosaic virus (ZaMV) (Chang 
et al. 2001), and Zantedeschia mild mosaic virus (ZaMMV) (Huang and Chang 2005). Among them, DsMV is a well-known potyvirus and reported in many kinds of aroid plants (Rana et al. 1983; Zettler and Hartman 1987). TuMV is an important cruciferous plant virus with a broad host range. ZaMV which was recently classified as the isolate of Konjak mosaic virus (KoMV) is probably the most prevalent virus infecting calla lily (Chang et al. 2001; Kwon et al. 2002; Nishiguchi et al. 2006; Huang et al. 2007). A newly identified calla virus, ZaMMV, was found widely spread in the fields in Taiwan and probably in other countries (Huang et al. 2007). The major symptoms of calla lily induced by these four viruses are mosaic, yellow stripe, green island and mild mosaic (Zettler and Hartman 1987; Chang et al. 2001; Pham et al. 2002; Chen et al. 2003; Huang and Chang 2005). CLLV alone does not produce symptoms in calla lilies and may not have a direct impact on the crop (Chen et al. 2004). For that reason we selected DsMV, TuMV, KoMV (ZaMV) and ZaMMV as the detection targets in our study. According to the field surveys in Taiwan, mixed infections by potyviruses are very common in calla lilies (Huang et al. 2007). Severe or mixed infection could cause leaf and flower distortion, stunting, growth reduction and yield loss (Hu et al. 2007).

Tissue culture is an important propagation method for calla lily in addition to tuber production in Taiwan. Viruses can be maintained within the plants during the growing season and storage stage due to systemic viral infection. Therefore, tissue culture together with reliable virus detection methods is essential for production of virus-free plantlets and tubers. Several detection methods for individual calla potyviruses were recently developed such as reverse transcription-polymerase chain reaction (RT-PCR), immunocapture RT-PCR (IC-RT-PCR), dot-blot hybridisation, and enzymelinked immunosorbent assay (ELISA) (Huang et al. 2005, 2007; Hu et al. 2007). These methods target only single viruses in one reaction. To save time and cost of virus detection, multiplex RT-PCR is chosen because it can rapidly detect multiple targets in one single assay with a small amount of sample. This technique has been successfully applied to many plants for virus detection, including apple (Menzel et al. 2002), citrus (Roy et al. 2005), olive (Bertolini et al. 2001), potato (Nie and Singh 2000; Du et al. 2006), orchids (Lee and Chang 2006), and other crops.
In this study, we established a multiplex RT-PCR system for simultaneous detection of four calla potyviruses in field samples. To rule out false negative results, one primer pair specific to plant mitochondrial NADH dehydrogenase (nad5) gene was incorporated to amplify the product of plant nad5 mRNA as the internal control. This is the first multiplex RT-PCR developed for aroid plants.

\section{Material and methods}

Virus isolates and plant materials

Four potyviruses, DsMV, TuMV, ZaMMV and KoMV (ZaMV), were previously isolated from calla lilies. Isolates of DsMV-ZAN (Chen et al. 1998), KoMV (ZaMV-ZAN) (Chang et al. 2001), ZaMMV-ZUN (Huang and Chang 2005) and TuMV-ZAN were separately maintained on tissue culture plantlets of cv. 'Black Magic' or Philodendron selloum by mechanical inoculation (Huang and Chang 2005). TuMV was also maintained in Nicotiana benthamiana. These plants were kept at $25^{\circ} \mathrm{C}$ with $16 \mathrm{~h}$ photoperiod in a greenhouse. For the disease survey, field-grown calla lily plants were randomly collected from the Taiwan Seed Improvement and Propagation Station (TSIPS) in Taichung County.

Plant total RNA extraction

Plant tissues collected from healthy, virus-inoculated and field grown plants were used to extract total RNA following the protocol of Plant Total RNA Extraction Miniprep System (Viogene, Sunnyvale, CA, USA). In brief, $0.1 \mathrm{~g}$ leaf tissue was ground into fine powder in liquid nitrogen and then transferred to a microfuge tube. After being mixed with $450 \mu \mathrm{PRX}$ extraction buffer, the lysate was filtered using a Shearing Tube. The filtrate was mixed with $230 \mu \mathrm{l}$ absolute ethanol, transferred to a new Plant Total RNA Mini Column, and filtered by centrifugation. This column was then washed once with WF Buffer and twice with WS Buffer. Finally, plant total RNA was eluted with $50 \mu \mathrm{l}$ RNase-free $d_{d H_{2}} \mathrm{O}$. The quality of total RNA was analysed by $1 \%$ agarose gel electrophoresis. Plant total RNA was used directly for RT-PCR or stored at $-20^{\circ} \mathrm{C}$ for further use. 
Primer design

Specific primer pairs of four calla potyviruses were designed based on the sequences of 3' terminal region of each individual virus, with the help of the Primer Premier 5 programme (Premier Biosoft Int., Palo Alto, CA, USA) to avoid primer dimer formation. The names, targets and sequences of primers and the expected product sizes are shown in Table 1 .

Viral and plant nad5 cDNA clones construction

Plant mitochondrial nad5 gene (mt) and four viral cDNA fragments were prepared from virus-infected plant total RNA by RT-PCR amplification. The firststrand cDNA was synthesised using dT-Bam (5'AGCTGGATCC $(\mathrm{T})_{18^{-}} 3^{\prime}$ ) or mtR1 primers. PCR reactions were carried out using dT-Bam and PNIbF1 (5'-GGBAAYAATAGTGGNCAACC-3') primers for potyviruses (Hsu et al. 2005), or $\mathrm{mtR} 1 / \mathrm{mtF} 2$ primers for plant mitochondrial nad5 gene gene. RT-PCR products were analysed in $1 \%$ agarose gels and the desired cDNA fragments were purified by $\mathrm{GFX}^{\mathrm{TM}}$ PCR DNA and Gel Band Purification Kit (Amersham Pharmacia Biotech, Piscataway, NJ, USA). The purified fragments were cloned into pGEM-T ${ }^{\circledR}$ Easy Vector (Promega, Madison, WI, USA). The correct cDNA clones were confirmed by sequencing and then used as templates for PCR experiments.

\section{Multiplex PCR}

Five pairs of reverse and forward primers (Table 1) were used in the multiplex PCR reaction. Different primer mixtures containing each primer $10 \times$ concentrated were prepared according to the experimental design. The final concentration of every primer was $0.125 \mu \mathrm{M}$ in original multiplex PCR. To adjust the primer ratio, TuMV primer concentration was decreased to 0.5 and $0.25 \times$ and DsMV primer was increased to $1.5 \times$ of original concentration $(0.125 \mu \mathrm{M})$. For multiplex PCR, the $20 \mu \mathrm{l}$ reaction mix contained $2 \mu \mathrm{l}$ template mixture ( 2 ng per cDNA clone), $2 \mu \mathrm{l} 10 \times$ primer mixture, $2 \mu \mathrm{l}$ $10 \times$ DyNAzyme $^{\mathrm{TM}}$ II DNA polymerase buffer (Finnzymes, Inc., Espoo, Finland), $0.5 \mu \mathrm{l}$ dNTPs $(10 \mathrm{mM})$, $0.5 \mu$ l DyNAzyme ${ }^{\mathrm{TM}}$ II DNA polymerase $\left(2 \mathrm{U} \mu \mathrm{l}^{-1}\right.$,

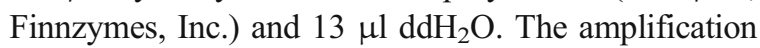
was carried out in GeneAmp ${ }^{\circledR}$ PCR system 2400 or 2700 (Perkin-Elmer Applied Biosystems, Foster City, CA, USA). PCR programme for DNA synthesis was $95^{\circ} \mathrm{C}$ for $5 \mathrm{~min}$, followed by 30 cycles of $95^{\circ} \mathrm{C}$ for $35 \mathrm{~s}, 56^{\circ} \mathrm{C}$ for $35 \mathrm{~s}, 72^{\circ} \mathrm{C}$ for $1 \mathrm{~min} 30 \mathrm{~s}$, and a final elongation step at $72^{\circ} \mathrm{C}$ for $7 \mathrm{~min}$. Eight microliter of PCR products were analysed by $1.5 \%$ agarose gel electrophoresis in 1X TAE buffer (40 mM Tris-acetate, 1 mM EDTA). The DNA fragments were stained with ethidium bromide for $10 \mathrm{~min}$ and examined under UV illumination.

\section{Multiplex RT-PCR}

The multiplex RT-PCR protocol has separate RT and PCR steps. Total RNA was extracted as described above. For $25 \mu \mathrm{l}$ RT reaction, $7 \mu$ l plant total RNA together with $2 \mu \mathrm{l}$ dT-Bam primer $(10 \mu \mathrm{M})$ and $1 \mu \mathrm{l}$ $\mathrm{mtR} 1$ primer $(5 \mu \mathrm{M})$ were heated at $65^{\circ} \mathrm{C}$ for $10 \mathrm{~min}$, cooled at $4^{\circ} \mathrm{C}$ for $5 \mathrm{~min}$ and then $15 \mu \mathrm{RT}$ mixture

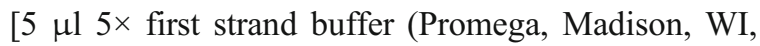

Table 1 The targets, names, sequences and the expected product sizes of the primer pair

\begin{tabular}{|c|c|c|c|c|}
\hline Target & Primers & Sequence $5^{\prime}-3^{\prime}$ & Product size & Reference \\
\hline TuMV & $\begin{array}{l}\text { TuR0 } \\
\text { TuCPF1 }\end{array}$ & $\begin{array}{l}\text { TGTCCCTTGCATCCTATCAAATGTT } \\
\text { GCAGGTGAGACGCTTGATGCAGG }\end{array}$ & $1077 \mathrm{bp}$ & This study \\
\hline ZaMMV & $\begin{array}{l}\text { ZUNR1 } \\
\text { ZUNF2 }\end{array}$ & $\begin{array}{l}\text { GTCCTTCACGAGTTTAGAGC } \\
\text { GATTCTCGACCTGGCTCATC }\end{array}$ & 792 bp & This study \\
\hline DsMV & $\begin{array}{l}\text { DR0 } \\
\text { DF2 }\end{array}$ & $\begin{array}{l}\text { TTGAACACCGTGCACGAAGCATC } \\
\text { GACTTCTATGAGGTCAATTC }\end{array}$ & $457 \mathrm{bp}$ & Huang et al. (2005) \\
\hline $\begin{array}{l}\text { KoMV } \\
\text { (ZaMV) }\end{array}$ & $\begin{array}{l}\text { ZR0 } \\
\text { ZF3 }\end{array}$ & $\begin{array}{l}\text { CTCCTATTTAAAAGACATGACTCG } \\
\text { CCGCCCTGCAAAGCGCAAAC }\end{array}$ & $260 \mathrm{bp}$ & Hu et al. (2007) \\
\hline nad5 mRNA & $\begin{array}{l}\mathrm{mtR} 1 \\
\mathrm{mtF} 2\end{array}$ & $\begin{array}{l}\text { ATCTCCAGTCACCAACATTGGCAT } \\
\text { GCTTCTTGGGGCTTCTTGTTCGATA }\end{array}$ & 185 bp & Lee and Chang (2006) \\
\hline
\end{tabular}


USA), $1 \mu \mathrm{l}$ dNTPs (10 mM), $0.5 \mu l$ rRNasin (40 $\mathrm{U}_{\mu} \mathrm{l}^{-1}$, Promega), $1 \mu \mathrm{l}$ AMV reverse transcriptase

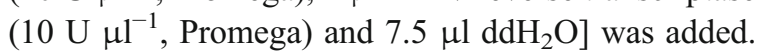
After incubating RT reaction solution at $42^{\circ} \mathrm{C}$ for $60 \mathrm{~min}$, the multiplex PCR reaction was performed as previously described except that $2 \mu \mathrm{l}$ RT product was used as template.

Indirect enzyme-linked immunosorbent assay (I-ELISA)

The antisera to DsMV, TuMV, ZaMMV and KoMV were previously prepared in our laboratory using recombinant capsid proteins as the antigens (Huang et al. 2005, 2007; $\mathrm{Hu}$ et al. 2007). I-ELISA was performed according to the protocol of Agdia Inc. (Elkhart, IN, USA) with some modification. One hundred milligrams of plant tissue was ground in $1 \mathrm{ml}$ of indirect sample extraction buffer [ISE buffer, $15 \mathrm{mM} \mathrm{Na}_{2} \mathrm{CO}_{3}, 35 \mathrm{mM} \mathrm{NaHCO} 3,2 \%$ polyvinylpyrrolidone (MW 40,000), $\mathrm{pH}$ 9.6]. One hundred microliter of the extracts were coated to the 96-well ELISA plate and then assayed as previously described (Lee and Chang 2008). Each sample assayed in triplicate. A sample was regarded as positive if the $A_{405}$ value exceeded twice the mean value of healthy controls.

\section{Results}

Specificity of detection primers tested by simplex and multiplex PCR

The performances of the designed primers were first tested using viral and plant nad5 cDNA clones as templates in simplex and multiplex PCR assays. The final concentration of each primer was $0.125 \mu \mathrm{M}$ in these PCR reactions. Initially, the specificity of individual primer pairs was analysed by PCR reaction with single cDNA template. The results of simplex PCR demonstrated that the expected PCR products were successfully generated by each single specific primer pair (Fig. 1a). When individual cDNA clones were tested by the multiplex PCR reaction, the expected fragments were specifically amplified by the primer mixture of TuMV, ZaMMV, DsMV, KoMV and mt control (Fig. 1b).
Although a lower yield of the products of DsMV, KoMV and $\mathrm{mt}$ were obtained in multiplex PCR compared with simplex PCR, all tested primers were specific to their targets. To further test the specificity of these primers with five templates simultaneously, the same amount of each individual cDNA clone was combined and then used for the multiplex PCR assay. According to the gel analysis, the PCR products of TuMV, ZaMMV, KoMV and mt control were successfully amplified but the DsMV fragment was hardly visible (Fig. 1c) indicating that the multiplex PCR needed modification in order to detect multiple targets.

\section{Optimisation of multiplex PCR reaction}

To optimise the multiplex PCR for detection of multiple targets, different concentration ratios of primer pairs were tested for amplification efficiency. In previous PCR assays, the same final concentration $(0.125 \mu \mathrm{M})$ of each primer was used and thus $0.125 \mu \mathrm{M}$ was assigned as ratio $1 \times$ in the primer ratio test. From our preliminary tests, DsMV amplification was hampered when using the same amount of TuMV and DsMV primers (data not shown). Consequently, five primer sets (I-V) with different primer ratios were prepared by decreasing TuMV primer ratio from 1 to 0.5 and $0.25 \times$, and at the same time increasing DsMV primer ratio to $1.5 \times$ (Fig. 2). At first individual viral and $\mathrm{mt}$ control templates were each tested by five sets of primer mixture, and all expected fragments were produced in multiplex PCR (Fig. 2a-d). Although the size of TuMV amplicon was the largest among five amplified targets, TuMV PCR product yield was reduced only slightly when its primer ratio was lowered to $0.25 \times$ (Fig. 2a, lanes 3 and 5). On the other hand, DsMV products increased when the primer ratio was raised to $1.5 \times$ (Fig. 2c, lanes 4 and 5). Furthermore, we tested the amplification efficiency of these primer mixtures with five cDNA templates simultaneously. The result clearly indicated that reducing the concentration of TuMV primer to ratio $0.25 \times$ allowed a significant increase in DsMV amplification rate and raising the DsMV primer ratio had a similar effect (Fig. 2e, lanes 3-5). Since primer sets III to V were able to amplify all five targets in multiplex PCR reaction, we chose the primer set $\mathrm{V}$ for subsequent RT-PCR experiments. 


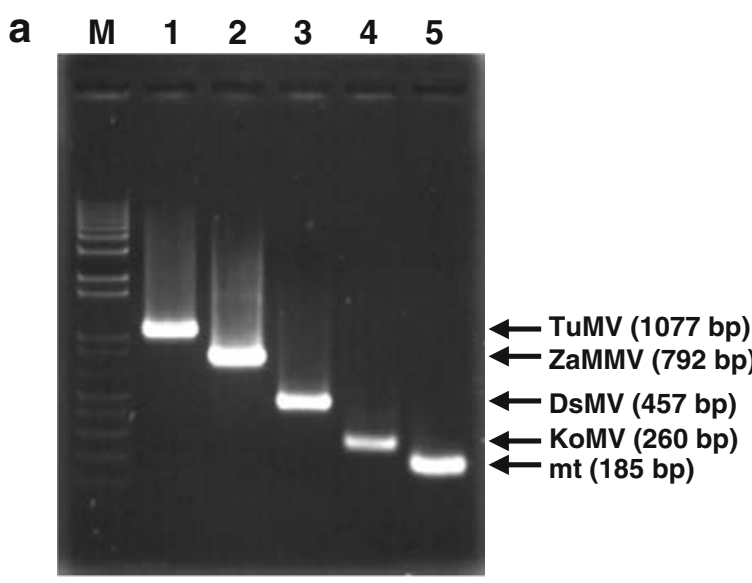

$\begin{array}{lllllll}\text { b } & \text { M } & 1 & 2 & 3 & 4 & 5\end{array}$
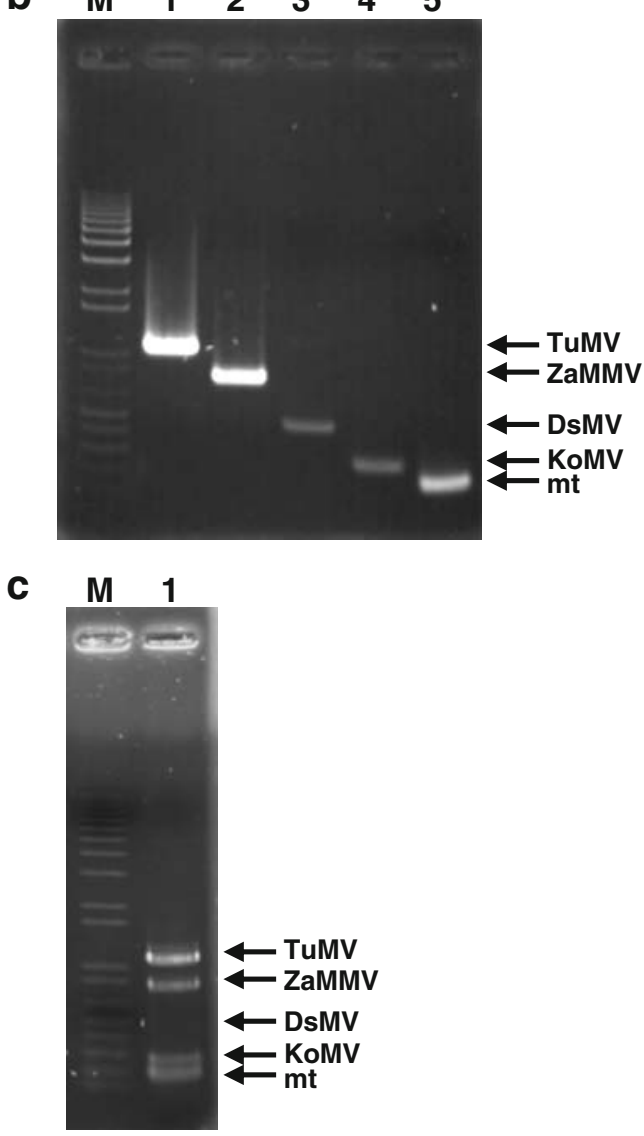

Specificity of multiplex RT-PCR against total RNAs from virus-infected plants

Purified total RNAs from calla lilies individually infected with TuMV, ZaMMV, DsMV and KoMV were used for cDNA synthesis using dT-Bam and
Fig. 1 Primer specificity tested by simplex and multiplex PCR using cDNA clones as templates. a The result of simplex PCR using single specific primer pair. b The result of multiplex PCR using the primer mixture of TuMV, ZaMMV, DsMV, KoMV and plant mitochondrial nad5 gene (mt). cDNA clones used for PCR analyses included TuMV (lane 1), ZaMMV (lane 2), DsMV (lane 3), KoMV (lane 4) and mt (lane 5). c The result of multiplex PCR with the template mixture and primer mixture of TuMV, ZaMMV, DsMV, KoMV and $\mathrm{mt}$. The final concentration of each primer was $0.125 \mu \mathrm{M}$. The PCR products separated by $1.5 \%$ agarose gel electrophoresis are indicated by arrows. Lane $M$ : $1 \mathrm{~kb}$ Plus DNA Ladder (Invitrogen, Carlsbad, CA, USA)

mtR1 primers and multiplex PCR was performed with the primer set $\mathrm{V}$. The correct virus targets were specifically amplified and the mt control fragment was consistently generated in all virus-infected samples (Fig. 3a). However, field-grown calla lilies are frequently infected by mixtures of two or more potyviruses. To test the ability to detect multiple viruses, artificial mixed-infection samples prepared by mixing two, three, or four different virus-infected plant total RNAs were assayed by multiplex RT-PCR. The expected RT-PCR products including virus and $\mathrm{mt}$ targets were correctly amplified in all tested virus combinations (Fig. 3b).

Comparison of detection sensitivity between multiplex RT-PCR and I-ELISA

To compare the detection sensitivity, the same amount of virus-infected calla lilies $(0.1 \mathrm{~g})$ were used to purify plant total RNA and to prepare original plant extract with 10 vol of ISE buffer. Afterwards five-fold serially diluted RNA and sap samples were prepared with healthy plant total RNA and extract as diluents, and then tested by multiplex RT-PCR and I-ELISA, respectively. The highest dilution at which multiplex RT-PCR showed positive result was $5^{-3}$ for TuMV, $5^{-4}$ for DsMV and KoMV, and $5^{-5}$ for ZaMMV. However, the detection limit of I-ELISA assay was determined as $5^{0}$ for KoMV, and $5^{-1}$ for TuMV, ZaMMV and DsMV (Fig. 4). Although KoMV had the lowest ELISA value in this test, the detecting limitation of multiplex RT-PCR still reached to $5^{-4}$ dilution (Fig. 4d). In summary, the detection sensitivity of multiplex RT-PCR was 25-625 times higher than that of I-ELISA depending on the virus. Although a 
Fig. 2 Optimisation of multiplex PCR reaction with different concentration ratios of the primer sets. Five different primer sets were used to test primer amplification efficiency with templates of internal control and single virus or four viruses. Each primer set contains five primer pairs and their primer concentration ratios are listed as a table. One represents the final concentration equal to $0.125 \mu \mathrm{M}$. Lanes $1-5$ indicated the PCR products amplified by primer set $\mathrm{I}-\mathrm{V}$, respectively. The results of multiplex PCR with templates of plant mitochondrial nad5 gene (mt) and TuMV (a), ZaMMV (b), DsMV (c), KoMV (d) or four viruses (e) were analysed by $1.5 \%$ agarose gel electrophoresis. The PCR products are indicated by arrows. Lane M: $1 \mathrm{~kb}$ Plus DNA Ladder (Invitrogen, Carlsbad, CA, USA)

\begin{tabular}{l|ccccc}
\hline primer & I & II & III & IV & V \\
\hline TuMV & 1 & 0.5 & 0.25 & 0.5 & 0.25 \\
ZaMMV & 1 & 1 & 1 & 1 & 1 \\
DsMV & 1 & 1 & 1 & 1.5 & 1.5 \\
KoMV & 1 & 1 & 1 & 1 & 1 \\
$\mathrm{mt}$ & 1 & 1 & 1 & 1 & 1 \\
\hline
\end{tabular}

\section{a}
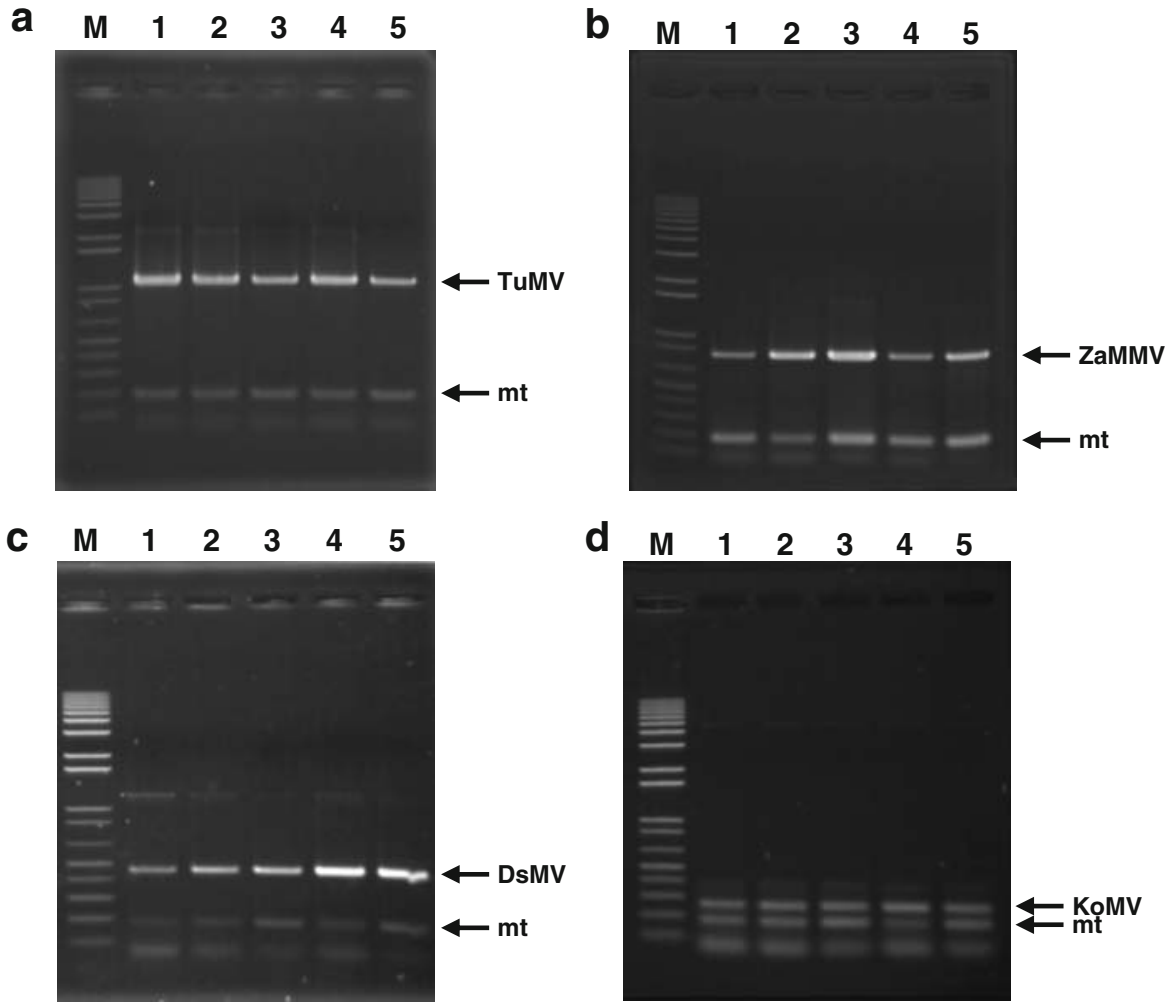

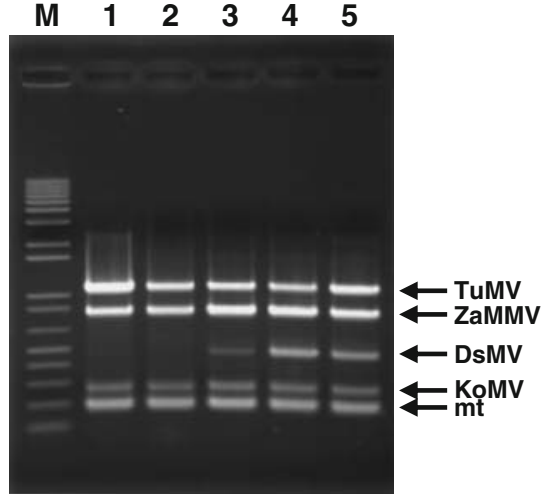

prozone effect in I-ELISA was noted for TuMV and ZaMMV when 1:10 (w/v) extracts were used compared with $1: 100(w / v)$ as suggested by AGDIA, use of the former had minimal effect on the results of final assay comparisons (data not shown).
Detection of calla potyviruses in field samples by multiplex RT-PCR and I-ELISA

Fifty full-expanded leaves of calla lily were randomly collected from the field of TSIPS in Taichung County. 

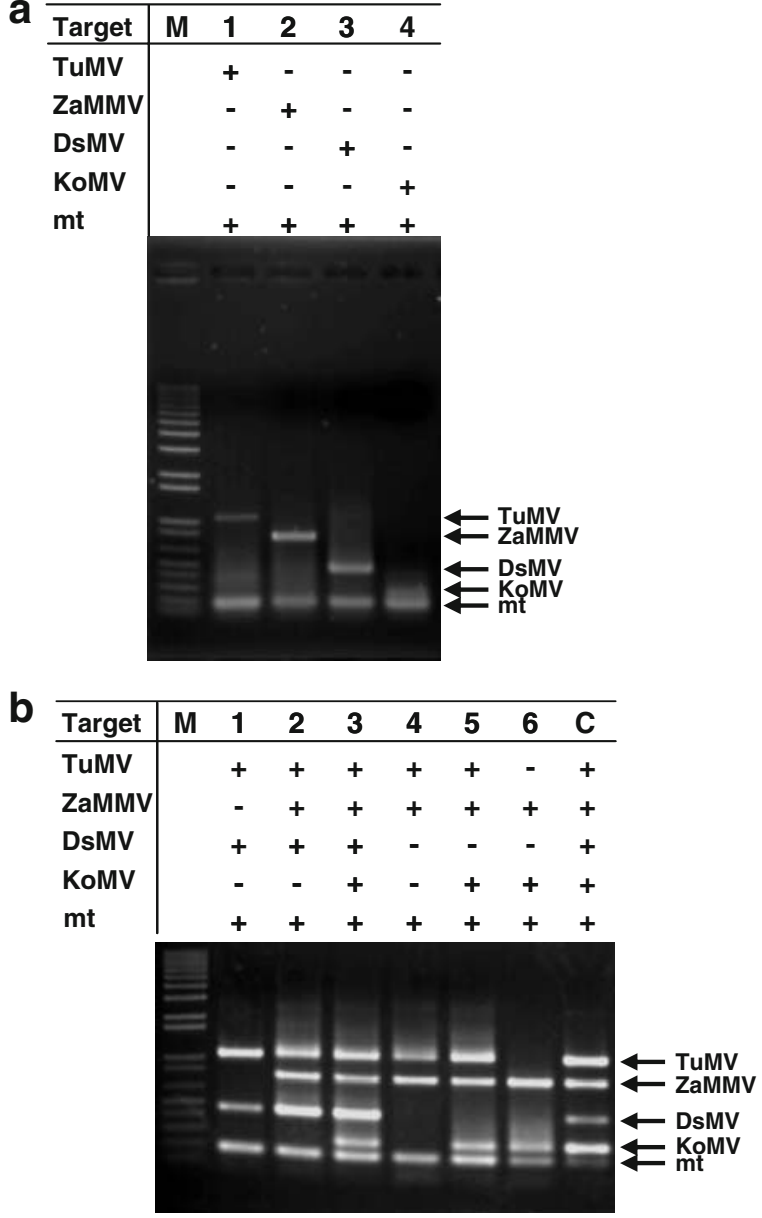

Fig. 3 Specificity of multiplex RT-PCR reaction with the primer set V. a Detection of single virus target and plant mitochondrial nad5 mRNA (mt) by multiplex RT-PCR reaction. Total RNAs derived from TuMV-infected (lane 1), ZaMMVinfected (lane 2), DsMV-infected (lane 3) and KoMV-infected (lane 4) plants were tested. The arrows indicate the RT-PCR product. b Detection of multiple virus targets and plant mitochondrial nad5 mRNA by multiplex RT-PCR reaction. Different combinations of virus-infected total RNAs are shown as a table. Lane $M: 1 \mathrm{~kb}$ Plus DNA Ladder (Invitrogen, Carlsbad, CA, USA). Lane $C$ : five cDNA clones used as positive control templates. RT-PCR products were analysed by $1.5 \%$ agarose gel electrophoresis and are indicated by arrows

These samples were used for the detection of calla potyviruses detection by multiplex RT-PCR and I-ELISA assays at the same time. According to the data, $72 \%(36 / 50)$ of calla lily samples tested positive for virus infection by multiplex RT-PCR, and about two thirds (23/36) of infected samples were mixed infections. By contrast, only $50 \%$ of the samples were positive in potyvirus-specific I-ELISA (Table 2). KoMV, found in $68 \%(34 / 50)$ and $44 \%(22 / 50)$ of the samples tested by multiplex RT-PCR and I-ELISA, was the dominant virus in the field. ZaMMV was identified in 44\% (22/50) and TuMV was detected in $22 \%(11 / 50)$ of calla lily plants by multiplex RT-PCR. The previously important aroid plant virus, DsMV, was only detected in one sample using multiplex RT-PCR (Table 2). It is apparent that the multiplex RT-PCR method had better sensitivity than I-ELISA to detect calla potyviruses in field samples.

\section{Discussion}

This paper describes a multiplex RT-PCR method for simultaneous detection of four potyviruses in calla lily with coamplification of a plant internal control. We selected DsMV, TuMV, ZaMMV and KoMV as the viral targets because these four viruses caused obvious symptoms and yield loss in calla lilies. In multiplex PCR, a DsMV fragment was barely amplified from a multiple-template mix when the final concentration of individual primer was equivalent (Fig. 1c). For unknown reasons, the TuMV primers seemed to interfere with the amplification of DsMV. We solved the problem by increasing the DsMV primer concentrations and decreasing the TuMV primer concentrations as well (Fig. 2). Although several studies indicated that short fragments are amplified more efficiently than longer fragments (Du et al. 2006; $\mathrm{Hu}$ et al. 2007), the amplification efficiency of the TuMV fragment was as good as other viral targets in all mixed samples (Figs. 2e and 3b). It might be due to the Tm value of TuMV primers $\left(64^{\circ} \mathrm{C}\right.$ and $\left.68^{\circ} \mathrm{C}\right)$ being higher than those of other viral primers, and hence more effectively amplifying the viral target during the PCR process. Even though short fragments were usually selected for multiple target detection, fragment size up to 814 and 942 bp were successfully used for virus detection in citrus trees (Roy et al. 2005). Consequently, large target fragments can still be utilised in multiplex system if the primer design and the PCR condition are optimised.

To avoid false negative results, different plant internal controls have been introduced into virus 
a
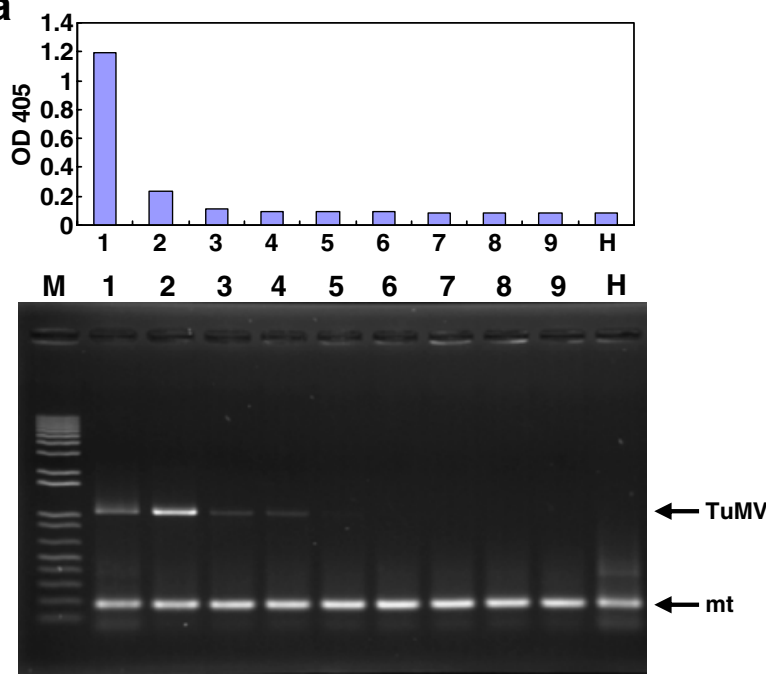

$\begin{array}{llllllllll}5^{0} & 5^{-1} & 5^{-2} & 5^{-3} & 5^{-4} & 5^{-5} & 5^{-6} & 5^{-7} & 5^{-8} & \mathrm{H}\end{array}$

b
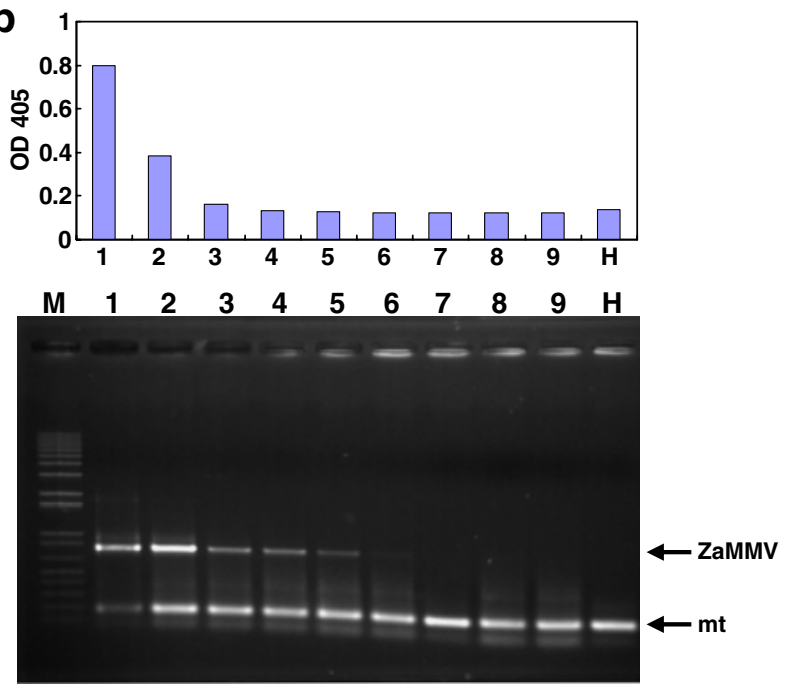

$\begin{array}{llllllllll}5^{0} & 5^{-1} & 5^{-2} & 5^{-3} & 5^{-4} & 5^{-5} & 5^{-6} & 5^{-7} & 5^{-8} & \mathrm{H}\end{array}$

Fig. 4 Comparison of detection sensitivity between multiplex RT-PCR and indirect ELISA (I-ELISA). Calla lily tissues infected by TuMV (a), ZaMMV (b), DsMV (c) or KoMV (d) were used to prepare original plant extracts and samples serially diluted five-fold with healthy leaf sap and then assayed by I-ELISA. Similarly, total RNA purified from TuMV-infected (a), ZaMMV-infected (b), DsMV-infected (c) or KoMV-

detection systems, such as 18S rRNA (Du et al. 2006), chloroplast NADH dehydrogenase ND2 subunit ( $n d h B)$ mRNA (Thompson et al. 2003) and mitochondrial NADH dehydrogenase (nad5 and
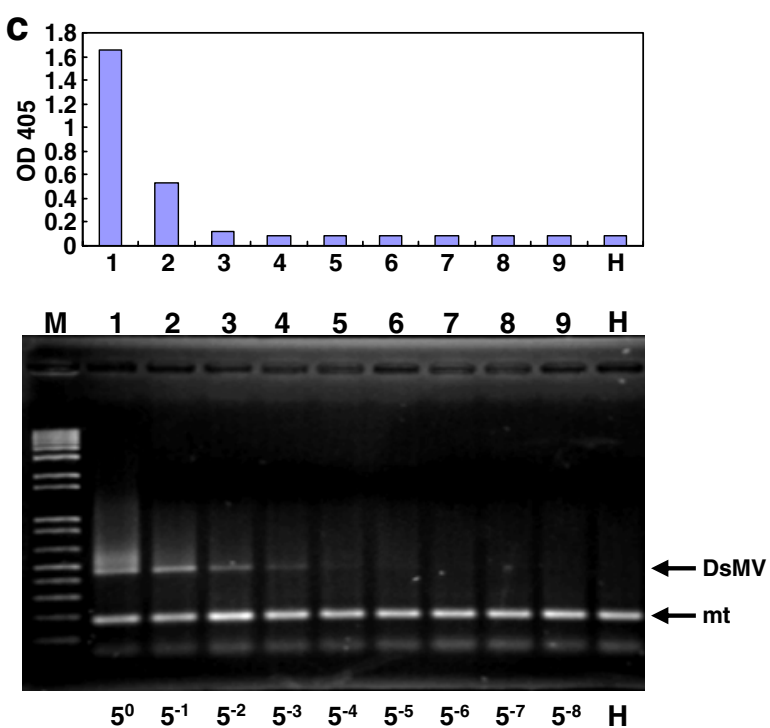

d
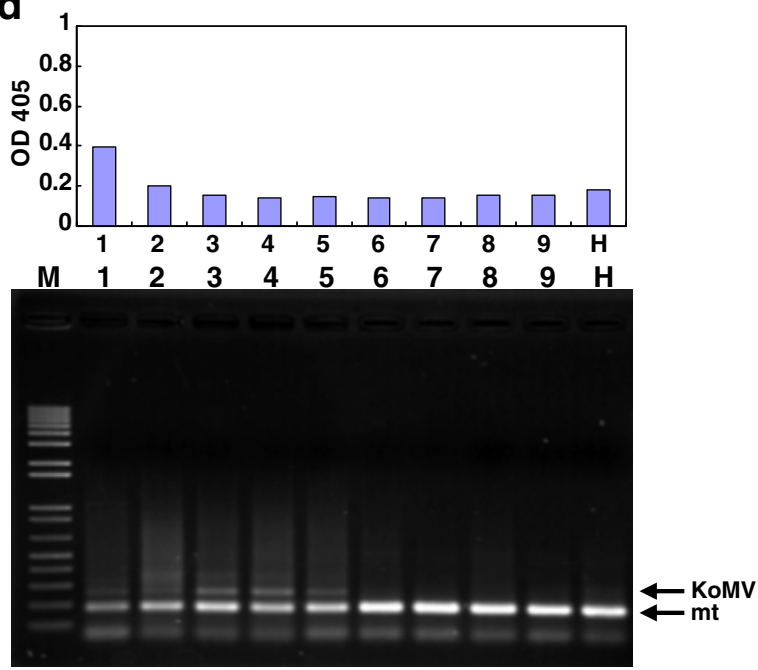

$\begin{array}{llllllllll}5^{0} & 5^{-1} & 5^{-2} & 5^{-3} & 5^{-4} & 5^{-5} & 5^{-6} & 5^{-7} & 5^{-8} & \mathrm{H}\end{array}$

infected (d) calla lily tissues were used to prepare samples serially diluted five-fold with healthy plant total RNA and then assayed by multiplex RT-PCR. Lanes $1-9$ indicated $5^{0}-5^{-8}$ serial dilutions. Lane M: $1 \mathrm{~kb}$ Plus DNA Ladder (Invitrogen, Carlsbad, CA, USA). Lane H: healthy plant control. RT-PCR products were analysed by $1.5 \%$ agarose gel electrophoresis and are indicated by arrows

nad2) mRNAs (Menzel et al. 2002; Du et al. 2006). Our previously designed $\mathrm{mt}$ primers, $\mathrm{mtF} 2$ and $\mathrm{mtR} 1$, consistently amplified a 185-bp cDNA fragment of nad5 mRNA from orchid total RNA (Lee and Chang 
Table 2 Number of samples (\% in parenthesis) of calla lilies collected from the field testing positive by indirect ELISA (I-ELISA) and multiplex RT-PCR (mRT-PCR) methods

\begin{tabular}{llc}
\hline Assay result $^{\mathrm{a}}$ & I-ELISA & mRT-PCR \\
\hline ZaMMV & $2(4 \%)$ & $1(2 \%)$ \\
KoMV & $4(8 \%)$ & $12(24 \%)$ \\
TuMV+ZaMMV & $1(2 \%)$ & $1(2 \%)$ \\
TuMV+KoMV & $1(2 \%)$ & $1(2 \%)$ \\
ZaMMV+KoMV & $10(20 \%)$ & $11(22 \%)$ \\
DsMV+KoMV & 0 & $1(2 \%)$ \\
TuMV+ZaMMV+KoMV & $7(14 \%)$ & $9(18 \%)$ \\
ND & $25(50 \%)$ & $14(28 \%)$ \\
Total & $50(100 \%)$ & $50(100 \%)$ \\
\hline
\end{tabular}

${ }^{\mathrm{a}} \mathrm{OD}_{405}$ value greater than twice the mean value of the healthy controls was considered as a positive sample. ND: sample did not react to four kinds of antisera or primers including TuMV, DsMV, ZaMMV and KoMV

2006). When the same primers were applied to calla lily, the amplified internal control fragments indicated the success of total RNA extraction and multiplex RT-PCR process (Fig. 3). Nevertheless, the consequences of our preliminary tests showed that the amplification efficiency of the nad5 fragment was greater than that of the potyvirus targets and sometimes interfered with virus amplification. Therefore, the mt primer was reduced to $1 / 4$ amount of oligo(dT) primer in RT step to lower first-strand cDNA synthesis of nad5 mRNA; the mt primer concentration was also adjusted from $0.25 \mu \mathrm{M}$ to $0.125 \mu \mathrm{M}$ in PCR step to improve the results (data not shown). In our opinion, the optimal primer concentration for a plant internal control is influenced by the features of plant species and viral targets, and needs adjustment in every virus detection system.

Due to the characteristic poly(A) tail at the $3^{\prime}$ end of potyvirus genome, we chose an oligo(dT) primer to synthesise first-strand cDNA of potyviruses. Nevertheless, the mtR 1 primer was used in addition to the oligo(dT) primer in the RT step to ensure sufficient cDNA synthesis of the plant internal control. In our system, utilisation of a universal oligo(dT) primer in the RT step lowered the primer complexity and the PCR conditions could be easily adjusted to facilitate the detection of virus containing a 3'-poly(A) tail.
Addition of specific primer pairs could expand the assay to detect calla viruses with and without 3 '-poly (A) tail as previously reported in potato virus detection (Nie and Singh 2000).

The detection limit of our multiplex RT-PCR was higher than I-ELISA according to the sensitivity comparison experiment. This was again confirmed by field disease survey, since multiplex RT-PCR identified more single as well as mixed infection samples than I-ELISA. From 50 calla lily plants randomly collected from the field, 36 samples tested positive for potyviruses by multiplex RT-PCR. KoMV and ZaMMV were the two dominant viruses found, in $68 \%$ and $44 \%$ of the tested samples respectively, and most of them from mixed infections. These data agreed with our investigation in the field survey during 2003-2004 (Huang et al. 2007). According to the prior report, field grown calla lily might be infected by TuMV through random transmission by the vectors from surrounding cruciferous crops (Chen et al. 2003). This might explain why widespread TuMV was found to infect calla lilies at a lower (22\%) infection rate. On the contrary, DsMV, the previously important virus of aroid plants, was only identified in one sample by multiplex RT-PCR. It might be due to routine indexing for DsMV in the micropropagation of calla lily by TSIPS and therefore decreased the viral disease incidence (Huang et al. 2007). In addition, we observed the internal control band remained consistent, whereas the intensities of individual viral fragments varied among tested field samples (data not shown). It suggested that the titer or distributions of viruses may be affected in mixed infections (Roy et al. 2005). From the above results, the detection of various combinations of viruses in field samples by the multiplex RTPCR assay demonstrated that this method will be useful in epidemiological studies of calla potyviruses.

The multiplex RT-PCR technique has been developed for several plant viruses but it is new to calla potyviruses. The sensitivity comparisons with I-ELISA indicated the value of the multiplex RT-PCR protocol. In conclusion, this multiplex RT-PCR assay provides a simple, rapid and reliable method for simultaneous detection of four potyviruses in calla lily. It also demonstrated the feasibility of this detection system in a disease diagnosis and certification programme of calla lily. 
Acknowledgements This study was supported by a grant from the National Science Council (NSC96-2317-B-002-002), Executive Yuan, Taiwan, R. O. C. We thank Mr. Ming-Chung Liu (TSIPS) for kind provision of calla lily samples, and $\mathrm{Mr}$. Ying-Lien Chen for preparation of DsMV cDNA clone and specific primer design.

\section{References}

Bertolini, E., Olmos, A., Martinez, M. C., Gorris, M. T., \& Cambra, M. (2001). Single-step multiplex RT-PCR for simultaneous and colourimetric detection of six RNA viruses in olive trees. Journal of Virological Methods, 92, 33-41.

Chang, Y.-C., Chen, Y.-L., \& Chung, F.-C. (2001). Mosaic disease of calla lily caused by a new potyvirus in Taiwan. Plant Disease, 85, 1289.

Chen, Y.-L., Chung, F.-C., \& Chang, Y.-C. (1998). Molecular cloning and characterization of Dasheen mosaic potyvirus from aroid plants in Taiwan. Plant Pathology Bulletin, 7, 226-227.

Chen, C.-C., Chao, C.-H., Chen, C.-C., Yeh, S.-D., Tsai, H.-T., \& Chang, C.-A. (2003). Identification of Turnip mosaic virus isolates causing yellow stripe and spot on calla lily. Plant Disease, 87, 901-905.

Chen, C.-C., Chang, C.-A., Tsai, H.-T., \& Hsu, H. T. (2004). Identification of a potyvirus causing latent infection in calla lilies. Plant Disease, 88, 1046.

Du, Z., Chen, J., \& Hiruki, C. (2006). Optimization and application of a multiplex RT-PCR system for simultaneous detection of five potato virus using $18 \mathrm{~S}$ rRNA as an internal control. Plant Disease, 90, 185-189.

Hsu, Y.-C., Yeh, T.-J., \& Chang, Y.-C. (2005). A new combination of RT-PCR and reverse dot blot hybridization for rapid detection and identification of potyviruses. Journal of Virological Methods, 128, 54-60.

Hu, W.-C., Lin, W.-F., Huang, W.-Z., Huang, C.-H., \& Chang, Y.-C. (2007). The production and application of the antiserum against Zantedeschia mosaic virus recombinant coat protein. Plant Pathology Bulletin, 16, 31-40.

Huang, C.-H., \& Chang, Y.-C. (2005). Identification and molecular characterization of Zantedeschia mild mosaic virus, a new calla lily-infecting potyvirus. Archives of Virology, 150, 1221-1230.

Huang, W.-Z., Chung, F.-C., Chen, Y.-L., Huang, C.-H., \& Chang, Y.-C. (2005). Development and comparison of three detection methods for calla lily-infecting Dasheen mosaic virus. Plant Pathology Bulletin, 14, 239-250.
Huang, C.-H., Hu, W.-C., Yang, T.-C., \& Chang, Y.-C. (2007). Zantedeschia mild mosaic virus, a new widespread virus in calla lily, detected by ELISA, dot-blot hybridization and IC-RT-PCR. Plant Pathology, 56, 183-189.

Kuehny, J. S. (2000). Crop reports: Calla history and culture. HortTechnology, 10, 267-274.

Kwon, S. B., Ha, J. H., Yoon, J. Y., \& Ryu, K. H. (2002). Zantedeschia mosaic virus causing leaf mosaic symptom in calla lily is a new potyvirus. Archives of Virology, 147, 2281-2289.

Lee, S.-C., \& Chang, Y.-C. (2006). Multiplex RT-PCR detection of two orchid viruses with an internal control of plant nad5 mRNA. Plant Pathology Bulletin, 15, 187-196.

Lee, S.-C., \& Chang, Y.-C. (2008). Performances and application of antisera produced by recombinant capsid proteins of Cymbidium mosaic virus and Odontoglossum ringspot virus. European Journal of Plant Pathology, 122, 297-306.

Menzel, W., Jelkmann, W., \& Maiss, E. (2002). Detection of four apple viruses by multiplex RT-PCR assays with coamplification of plant mRNA as internal control. Journal of Virological Methods, 99, 81-92.

Nie, X., \& Singh, R. P. (2000). Detection of multiple potato viruses using an oligo(dT) as a common cDNA primer in multiplex RT-PCR. Journal of Virological Methods, 86, 179-185.

Nishiguchi, M., Yamasaki, S., Lu, X.-Z., Shimoyama, A., Hanada, K., Sonoda, S., et al. (2006). Konjak mosaic virus: the complete nucleotide sequence of the genomic RNA and its comparison with other potyviruses. Archives of Virology, 151, 1643-1650.

Pham, K., Langeveld, S. A., Lemmers, M. E. C., \& Derks, A. F. L. M. (2002). Detection and identification of potyviruses in Zantedeschia. Acta Horticulturae, 568, 143-148.

Rana, G. L., Vovlas, C., \& Zettler, F. W. (1983). Manual transmission of Dasheen mosaic virus from Richardia to nonaraceous host. Plant Disease, 67, 1121-1122.

Roy, A., Fayad, A., Barthe, G., \& Brlansky, R. H. (2005). A multiplex polymerase chain reaction method for reliable, sensitive and simultaneous detection of multiple viruses in citrus trees. Journal of Virological Methods, 129, 47-55.

Thompson, J. R., Wetzel, S., Klerks, M. M., Vaskova, D., Schoen, C. D., Spak, J., et al. (2003). Multiplex RT-PCR detection of four aphid-borne strawberry viruses in Fragaria spp. in combination with a plant mRNA specific internal control. Journal of Virological Methods, 111, 8593.

Zettler, F. W., \& Hartman, R. D. (1987). Dasheen mosaic virus as a pathogen of cultivated aroids and control of the virus by tissue culture. Plant Disease, 71, 958-963. 